\title{
Papers
}

\section{Antidepressant treatment and the risk of fatal and non-fatal self harm in first episode depression: nested case-control study}

Carlos Martinez, Stephan Rietbrock, Lesley Wise, Deborah Ashby, Jonathan Chick, Jane Moseley, Stephen Evans, David Gunnell

\begin{abstract}
Objective To compare the risk of non-fatal self harm and suicide in patients taking selective serotonin reuptake inhibitors (SSRIs) with that of patients taking tricyclic antidepressants, as well as between different SSRIs and different tricyclic antidepressants.

Design Nested case-control study.

Setting Primary care in the United Kingdom.

Participants 146095 individuals with a first prescription of an antidepressant for depression.

Main outcome measures Suicide and non-fatal self harm. Results 1968 cases of non-fatal self harm and 69 suicides occurred. The overall adjusted odds ratio of non-fatal self harm was $0.99(95 \%$ confidence interval 0.86 to 1.14$)$ and that of suicide 0.57 ( 0.26 to 1.25 ) in people prescribed SSRIs compared with those prescribed tricyclic antidepressants. We found little evidence that associations differed over time since starting or stopping treatment. We found some evidence that risks of non-fatal self harm in people prescribed SSRIs compared with those prescribed tricyclic antidepressants differed by age group (interaction $\mathrm{P}=0.02$ ). The adjusted odds ratio of non-fatal self harm for people prescribed SSRIs compared with users of tricylic antidepressants for those aged 18 or younger was 1.59 (1.01 to 2.50), but no association was apparent in other age groups. No suicides occurred in those aged 18 or younger currently or recently prescribed tricyclic antidepressants or SSRIs.

Conclusion We found no evidence that the risk of suicide or non-fatal self harm in adults prescribed SSRIs was greater than in those prescribed tricyclic antidepressants. We found some weak evidence of an increased risk of non-fatal self harm for current SSRI use among those aged 18 or younger. However, preferential prescribing of SSRIs to patients at higher risk of suicidal behaviour cannot be ruled out.
\end{abstract}

Topic: $83 ; 576 ; 299 ; 208$

\section{Introduction}

Since the introduction of selective serotonin reuptake inhibitor (SSRI) antidepressants, concerns have been that these drugs may increase the risk of suicidal behaviour. ${ }^{1-3}$ Although analyses of data in adults have not consistently shown any influence on suicide or self harm from use of SSRIs, ${ }^{4}$ randomised controlled trials in young people indicate that these drugs may increase the risk of suicidal thoughts and self harm in those aged under $19 .{ }^{56}$ Ecological studies provide mixed evidence on the risks and benefits of SSRIs-some show that increases in SSRI prescribing are associated with reductions in suicide rates in the population; others show the opposite. ${ }^{4}$

The most comprehensive studies of suicidal behaviour to date are based on the General Practice Research Database. ${ }^{78}$ The first study contrasted the risks of suicide in people taking antidepressants commonly prescribed between 1988 and 1993. Although this study found some evidence of an increased risk of suicide among people prescribed fluoxetine, ${ }^{7}$ it was difficult to interpret because the drug's safety in overdose may have led to selective prescription to people at risk of self harm. Another study $^{8}$ compared the risks for suicide and non-fatal suicidal behaviour between people prescribed fluoxetine, paroxetine, amitriptyline, and dothiepin in 1993 to 1999. No notable differences were found between the drugs in risk for fatal or non-fatal suicidal behaviour. The study was not restricted to patients prescribed antidepressants for the treatment of depression, making comparisons between individual SSRIs and tricyclic antidepressants more liable to confounding.

We report a nested case-control study, based on the General Practice Research Database, of patients with a new diagnosis of depression who were prescribed antidepressants for the first time between 1995 and 2001. We compared the risk of non-fatal self harm and suicide in association with the use of SSRIs and tricyclic antidepressants.

\section{Methods \\ Materials}

The General Practice Research Database contains anonymised clinical records from primary care in the United Kingdom. ${ }^{9}$ Our study cohort came from this database and comprised patients aged 90 years or younger with a first recorded prescription for antidepressants between 1 January 1995 and 31 December 2001. The date of the first prescription defined entry to the cohort. Members of the cohort were required to have contributed a minimum of 365 days to the database before their first recorded prescription for antidepressants and to have received a diagnosis of depression in the 180 days before or 90 days after entry to the cohort. Follow up ended with the earliest of either an episode of suicidal behaviour, the end of the first treatment episode, the end date of the study, or when the patient left the practice. People with an episode of non-fatal self harm were not censored in analyses with suicide as the end point.

A classification system for the severity of depression, the method used to measure exposure to antidepressants, and supplemental tables are on bmj.com 
We identified depression by a set of Read and Oxford Medical Information System (OXMIS) medical terms indicative of depression, bipolar disorder, or dysthymic disorder. We classed severity of depression as mild, moderate, or severe (see bmj.com).

We categorised antidepressants into three classes: tricyclic and related antidepressants (amitriptyline, amoxapine, clomipramine, dosulepin or dothiepin, doxepin, imipramine, lofepramine, nortriptyline, trimipramine, maprotiline, mianserin, and trazodone), SSRIs (citalopram, fluoxetine, fluvoxamine, paroxetine, and sertraline), and other antidepressants (flupenthixol, mirtazapine, reboxetine, tryptophan, venlafaxine, and the monoamine oxidase inhibitors phenelzine, isocarboxazid, tranylcypromine, and moclobemide).

We studied the two outcomes of non-fatal self harm and suicide. We identified cases of suicide from a list of OXMIS or Read medical terms, review of all free text entries for patients who had died of any cause, and death certificates when available (around $60 \%$ of cases). Using this information we assessed the likelihood, the method, and the date of suicide.

We identified cases of non-fatal self harm (drug overdose, deliberate self laceration, poisoning, and non-fatal suicide attempts using other methods) by using relevant OXMIS or Read medical terms and review of the patient's free text notes.

We selected a random sample of up to 20 controls for each case from the cohort, matching for sex, year of birth within one year, and duration of cohort membership to the nearest day for participants with membership of less than 60 days, nearest 10 days if membership was 60 to 365 days, and one month if cohort membership was more than one year. We derived the duration of prescriptions from the quantity of drug prescribed and the daily dose plus an additional seven day washout period (see bmj.com).

\section{Data analysis}

We classified the cases and controls as currently or previously exposed to an SSRI, tricyclic antidepressant, or other antidepressant, or co-exposed to more than one antidepressant, according to the exposure status on the index day (day of self harm or suicide or equivalent control day). We standardised the incidence rates for non-fatal self harm and suicide to the UK population in 2001. ${ }^{10} 11$

We assessed risks associated with "current exposure." We used multivariable conditional logistic regression to estimate adjusted odds ratios and 95\% confidence intervals. In the models that compared non-fatal self harm associated with different classes of antidepressants, we prespecified monotherapy with a tricyclic antidepressant as the reference group. We used monotherapy with paroxetine and monotherapy with dothiepin as the reference categories for the respective comparisons within drug classes. We controlled for severity of depression, referral to a psychiatrist or psychologist, history of non-fatal self harm, diagnosis of or treatment for anxiety or panic disorder, schizophrenia, antipsychotic drugs, drug misuse, alcohol misuse, current lithium treatment, number of antidepressants prescribed in the previous year, and time difference between diagnosis of depression and start of treatment.

We investigated whether risk varied in relation to duration of current use of antidepressants, time since stopping treatment, and age at entry to the cohort $(10-18,19-30$, and >30). We defined the youngest age group on the basis that a possible increased risk of suicidal behaviour has been shown among people aged up to and including 18 who have been prescribed SSRIs. This age categorisation of paediatric patients is in keeping with international regulatory guidelines. ${ }^{12}$ The General Practice Research Database does not hold the date of birth but only the year of birth, and therefore the age at the event date could fluctuate by up to one year from the real age.

We stratified the duration of exposure (days) to antidepressants into four categories $(<14,15-30,31-60,>60)$ after the start of treatment with antidepressants. Time since discontinuation was stratified into the same four categories according to the end date of the prescription. In all comparisons, we compared SSRI monotherapy with tricylic antidepressant monotherapy for the same duration of either current or past exposure. We used likelihood ratio tests to carry out heterogeneity tests. We do not present odds ratios based on fewer than three cases or controls in either group. We used Stata, release 8 (College Station, TX: StataCorp), for all analyses.

\section{Results}

Our study cohort included 146095 patients with a first prescription for an antidepressant for depression. These patients contributed 62224 person years of follow up to the cohort (see bmj.com). Table 1 lists the characteristics of the participants, classified according to the first antidepressant prescribed. Almost twice as many women as men received antidepressants. SSRIs were the most commonly prescribed antidepressants. People prescribed SSRIs tended to be younger and more often had a history of self harm and referral to psychiatrists than those prescribed tricyclic antidepressants.

Table 2 shows data on exposures to antidepressants by age group. The strongest predictors of non-fatal self harm were a history of self harm, referral to a psychiatrist, alcohol misuse, and drug misuse. The strongest predictors for suicide were a history of non-fatal self harm, antipsychotic therapy, number of antidepressants prescribed in the previous year, alcohol misuse, and referral to a psychiatrist (table 3).

Over the study period, 1968 people had a recorded an episode of non-fatal self harm: 1344 were exposed to antidepressant medication at the time, and 624 had stopped treatment before the episode. Drug overdose accounted for most episodes of non-fatal self harm (81\%). The incidence rate of non-fatal self harm, standardised by age and sex, per 100000 person years of follow up among people prescribed antidepressants was 2894 (95\% confidence interval 2618 to 3170). The rate per 100000 person years for men was 2834 (2579 to 3089) and for women was 2952 (2471 to 3432).

Overall, 69 suicides took place (56 men, 13 women); 36 of those people were taking antidepressants at the time of death. The overall standardised incidence rate for suicide was 62 (40 to 85) per 100000 person years; in men this was 117 (72 to 163) and in women 9 (1 to 18 ).

Table 4 shows the association of current antidepressant use with non-fatal self harm and suicide for all ages. The adjusted odds ratio for non-fatal self harm among SSRI users compared with users of tricyclic antidepressants was 0.99 (0.86 to 1.14). We found no evidence that the risk of non-fatal self harm varied among the different individual SSRIs or tricyclic antidepressants $(\mathrm{P}=0.35$ and $\mathrm{P}=0.69$, respectively $)$ and no evidence of an increased risk of suicide associated with use of SSRIs compared with tricyclic antidepressants (odds ratio $0.57,0.26$ to 1.25 ).

We found borderline evidence that the risk of non-fatal self harm ( $\mathrm{P}$ for interaction $=0.05)$, but not suicide $(\mathrm{P}$ for interaction $=0.73$ ), differed between the different antidepressant categories in relation to time since starting therapy (table 5). This association showed no clear pattern.

We found evidence of a difference in risk of non-fatal self harm for current SSRI users compared with current users of tri- 
Table 1 Characteristics of study cohort according to first antidepressant class prescribed. Values are numbers (percentages) unless otherwise indicated Characteristic SSRIs ( $\mathrm{n}=90$ 403) Tricyclic antidepressants ( $\mathrm{n}=50$ 829) Other antidepressants ( $\mathrm{n}=\mathbf{4 8 6 3 )}$ Total ( $\mathrm{n}=146$ 095) Age in years:

\begin{tabular}{|c|c|c|c|c|}
\hline 10-18 & $3830(4)$ & $1316(3)$ & $141(3)$ & $5287(4)$ \\
\hline $19-30$ & $23561(26)$ & $10145(20)$ & $1086(22)$ & $34792(24)$ \\
\hline $31-45$ & $31541(35)$ & $15431(30)$ & $1548 \quad(32)$ & $48520(33)$ \\
\hline $46-60$ & $18310(20)$ & $11506(23)$ & $989(20)$ & $30805(21)$ \\
\hline $61-75$ & $7949(9)$ & 7538 (15) & $605(12)$ & $16092(11)$ \\
\hline $76-89$ & $5212(6)$ & $4893(10)$ & $494(10)$ & $10599(7)$ \\
\hline Women & $58444(65)$ & $33399(66)$ & $2924(60)$ & $94767(65)$ \\
\hline Men & $31959(35)$ & $17430(34)$ & $1939(40)$ & $51328(35)$ \\
\hline $\begin{array}{l}\text { Median (interquartile range) duration } \\
\text { of observation (years) }\end{array}$ & $0.67(0.57-1.03)$ & $0.65(0.57-1.02)$ & $0.65(0.57-1.02)$ & $0.66(0.57-1.03)$ \\
\hline \multicolumn{5}{|l|}{ Severity of depression: } \\
\hline Mild & $60537(67)$ & $36893(72)$ & $3306(68)$ & $100736(69)$ \\
\hline Moderate & $26710(30)$ & $12116(24)$ & $1329(27)$ & $40155(27)$ \\
\hline Severe & $3156(3)$ & $1820(4)$ & $228(5)$ & $5204(4)$ \\
\hline $\begin{array}{l}\text { Referral to psychiatrist or } \\
\text { psychologist }^{\star}\end{array}$ & 721 (1) & $211(0)$ & $75(2)$ & 1007 (1) \\
\hline History of self harm† & $479(1)$ & $201(0)$ & $33(1)$ & $713(<1)$ \\
\hline \multicolumn{5}{|l|}{ Concomitant conditions: } \\
\hline $\begin{array}{l}\text { Diagnosis of, or therapy for, } \\
\text { anxiety and panic disorders }\end{array}$ & $21501(24)$ & $11209(22)$ & $1476(30)$ & $34186(23)$ \\
\hline Schizophrenia & $101(0)$ & $97(0)$ & $10(0)$ & $208(0)$ \\
\hline Antipsychotic therapy & $2947(3)$ & $1916(4)$ & $252(5)$ & $5115(4)$ \\
\hline Drug misuse & $61(0)$ & $45(0)$ & $3(0)$ & $109(0)$ \\
\hline Alcohol misuse & $2408(3)$ & $1269(2)$ & $184(4)$ & $3861 \quad(3)$ \\
\hline
\end{tabular}

*In year previous to index day.

†Includes drug overdose, poisoning, self laceration, and other non-fatal suicidal attempts before entry to cohort

cyclic antidepressants in relation to age $(\mathrm{P}$ for interaction $=0.02)$, with an increased risk associated with SSRI use among those aged 18 or younger (odds ratio $1.59,1.01$ to 2.50 ), but not in 19 to 30 year olds $(1.04,0.82$ to 1.31$)$ or those younger than 30 $(0.86,0.71$ to 1.04 ; table 6$)$.

In people aged 18 or younger, we found no evidence of any difference in risk of non-fatal self harm between individual tricyclic antidepressants, but among SSRIs (figure), the greatest risk was in relation to paroxetine use.

The risk of non-fatal self harm or suicide did not seem to differ between or within antidepressant classes according to the time since stopping treatment (see bmj.com).

\section{Discussion}

In patients with newly diagnosed depression treated with antidepressants for the first time, we have found no evidence that the risk of suicide in people currently prescribed SSRIs is higher than in those prescribed tricyclic antidepressants.
Likewise, we found no differences overall in the risk of nonfatal self harm between people prescribed SSRIs and those prescribed tricyclic antidepressants. However, we found some evidence that the risk of non-fatal self harm among people prescribed SSRIs differed with age. In patients aged 18 or younger, but not older subjects, risks were higher in people prescribed SSRIs than with tricyclic antidepressants. Consistent with the findings of a recent study by Jick et al, ${ }^{8}$ we found no overall evidence of significant variability in the risk of non-fatal self harm between substances or between drug classes associated with time since starting antidepressant therapy. We also found no evidence overall of a difference between SSRIs and tricyclic antidepressants in the risk of non-fatal self harm or suicide on stopping treatment. In young people (younger than 18), we found a weak indication that the risk of non-fatal self harm among users of the SSRIs studied is highest in those who used paroxetine. This is in keeping with the finding by Jick et al, of no substantial difference in the effects of the antidepressants they studied on people aged

Table 2 Age and sex distribution of cases of non-fatal self harm and suicide and their matched controls

\begin{tabular}{|c|c|c|c|c|}
\hline \multirow[b]{2}{*}{ Exposure } & \multicolumn{2}{|c|}{ Non-fatal self harm } & \multicolumn{2}{|c|}{ Completed suicides } \\
\hline & Cases $(n=1968)$ & Controls ( $n=34$ 494) & Cases $(n=69)$ & Controls $(n=1121)$ \\
\hline \multicolumn{5}{|l|}{ Age at index date in years } \\
\hline 10-18: & 285 & 4567 & 0 & 0 \\
\hline Currently exposed to antidepressants & 210 & 2809 & 0 & 0 \\
\hline Stopped antidepressants in previous 180 days & 75 & 1758 & 0 & 0 \\
\hline 19-30: & 747 & 13531 & 19 & 339 \\
\hline Currently exposed to antidepressants & 482 & 7212 & 7 & 146 \\
\hline Stopped antidepressants in previous 180 days & 265 & 6319 & 12 & 193 \\
\hline$>30:$ & 936 & 16396 & 50 & 778 \\
\hline Currently exposed to antidepressants & 652 & 9932 & 30 & 522 \\
\hline Stopped antidepressants in previous 180 days & 284 & 6464 & 20 & 256 \\
\hline Women & 1105 & 19847 & 13 & 229 \\
\hline$\overline{\text { Men }}$ & 863 & 14647 & 56 & 892 \\
\hline
\end{tabular}


Table 3 Odds ratios for the association of potential confounders with non-fatal self harm and completed suicides

\begin{tabular}{|c|c|c|c|c|c|c|}
\hline \multirow[b]{2}{*}{ Variable } & \multicolumn{3}{|c|}{ Non-fatal self harm } & \multicolumn{3}{|c|}{ Completed suicides } \\
\hline & $\begin{array}{c}\text { Cases } \\
(n=1968)\end{array}$ & $\begin{array}{c}\text { Controls ( } n=34 \\
494)\end{array}$ & Crude odds ratio $(95 \% \mathrm{Cl})^{*}$ & Cases $(n=69)$ & $\begin{array}{l}\text { Controls } \\
(n=1121)\end{array}$ & Crude odds ratio $(95 \% \mathrm{Cl})$ \\
\hline \multicolumn{7}{|l|}{ Severity of depression: } \\
\hline Mild & 1260 & 22095 & 1 & 54 & 785 & 1 \\
\hline Moderate & 601 & 11047 & 0.98 (0.88 to 1.08$)$ & 13 & 293 & 0.64 (0.33 to 1.22$)$ \\
\hline Severe & 107 & 1352 & 1.43 (1.16 to 1.76$)$ & 2 & 43 & - \\
\hline $\begin{array}{l}\text { Referral to psychiatrist or } \\
\text { psychologist } †\end{array}$ & 202 & 891 & 4.10 (3.48 to 4.84$)$ & 6 & 26 & 3.41 (1.28 to 9.05$)$ \\
\hline History of self harm $\ddagger$ & 64 & 134 & 9.14 (6.73 to 12.4$)$ & 3 & 4 & 15.0 (3.36 to 67.0$)$ \\
\hline $\begin{array}{l}\text { Diagnosis of, or treatment for, } \\
\text { anxiety or panic disorder }\end{array}$ & 643 & 7888 & 1.67 (1.51 to 1.85 ) & 19 & 228 & 1.60 (0.91 to 2.82) \\
\hline Schizophrenia & 2 & 8 & 1.82 (0.32 to 10.5$)$ & 1 & 3 & - \\
\hline Antipsychotic therapy & 255 & 1908 & 2.40 (2.08 to 2.77$)$ & 12 & 46 & 4.67 (2.30 to 9.51$)$ \\
\hline Drug misuse & 2 & 9 & 2.90 (0.61 to 13.8$)$ & 0 & 2 & - \\
\hline Alcohol misuse & 213 & 1173 & 3.58 (3.04 to 4.21$)$ & 7 & 53 & 2.31 (0.97 to 5.49) \\
\hline Lithium therapy§ & 23 & 182 & 1.81 (1.16 to 2.83$)$ & 0 & 6 & - \\
\hline \multicolumn{7}{|l|}{$\begin{array}{l}\text { No of different antidepressants } \\
\text { prescribed§: }\end{array}$} \\
\hline 0 & 715 & 19536 & 1 & 27 & 673 & 1 \\
\hline 1 & 807 & 11544 & 1.97 (1.77 to 2.19 ) & 29 & 365 & 2.05 (1.18 to 3.59 ) \\
\hline 2 or 3 & 422 & 3232 & 3.65 (3.19 to 4.18$)$ & 12 & 82 & 3.42 (1.57 to 7.43 ) \\
\hline$>3$ & 24 & 182 & 3.41 (2.18 to 5.33$)$ & 1 & 1 & - \\
\hline
\end{tabular}

*Values not shown for age and sex as they were matching variables.

†ln year before index day.

łlncludes drug overdose, deliberate poisoning, self laceration, and other methods of self harm before entry to cohort.

$\S$ In year before index day and since entry to cohort.

10 to 19 years, but that important differences could not be ruled out. $^{8}$

\section{Limitations}

Our study has several potential limitations that may have influenced our results. A major concern in observational studies is when the outcome under study is itself an indication for which the drug might be prescribed. ${ }^{13}$ SSRIs are relatively non-toxic in overdose $^{14}$ compared with tricyclic antidepressants, and it is therefore possible that they were selectively given to individuals thought to be at higher risk of overdose and that SSRI overdose did not result in admission to hospital or the patient presenting at the general practice. Previous self harm is an important predictor of further self harm and suicide. ${ }^{15}$ Although we had information on recorded past self harm, the prevalence of such behaviours among study members who harmed themselves $(<5 \%)$ is considerably lower than reported among case series of people who harmed themselves $(50 \%)^{16}$ and completed suicides $(30 \%$ to $47 \%),{ }^{17}$ which indicates the possibility of residual confounding if non-fatal self harm is recorded differentially for SSRIs compared with tricyclic antidepressants. Three other limitations are worth noting. Firstly, we assumed prescribing to be a marker for exposure, but not all prescriptions are dispensed, and

Table 4 Risk of non-fatal self harm and completed suicide in people prescribed SSRIs, other antidepressants, or exposed to more than one antidepressant compared with people prescribed tricylic antidepressants and among specific SSRIs compared with paroxetine and specific tricyclic antidepressants compared with dothiepin (all ages)

\begin{tabular}{|c|c|c|c|c|c|c|c|c|}
\hline \multirow[b]{2}{*}{ Exposure } & \multicolumn{4}{|c|}{ Non-fatal self harm } & \multicolumn{4}{|c|}{ Completed suicides } \\
\hline & $\begin{array}{c}\text { Cases } \\
(\mathrm{n}=1344)\end{array}$ & $\begin{array}{c}\text { Controls } \\
(\mathrm{n}=19953)\end{array}$ & $\begin{array}{c}\text { Crude odds ratio (95\% } \\
\text { CI) }\end{array}$ & $\begin{array}{c}\text { Adjusted odds ratio* } \\
(95 \% \mathrm{Cl})\end{array}$ & $\begin{array}{l}\text { Cases } \\
(n=36)\end{array}$ & $\begin{array}{r}\text { Controls } \\
(\mathrm{n}=664)\end{array}$ & $\begin{array}{l}\text { Crude odds ratio (95\% } \\
\text { CI) }\end{array}$ & $\begin{array}{l}\text { Adjusted odds ratio* } \\
(95 \% \mathrm{Cl})\end{array}$ \\
\hline $\begin{array}{l}\text { Any current use of } \\
\text { tricylic antidepressant }\end{array}$ & 319 & 4901 & 1 & 1 & 15 & 201 & 1 & 1 \\
\hline $\begin{array}{l}\text { Any current use of } \\
\text { SSRIs }\end{array}$ & 854 & 13636 & 0.97 (0.85 to 1.12$)$ & 0.99 (0.86 to 1.14$)$ & 17 & 406 & 0.59 (0.28 to 1.27$)$ & 0.57 (0.26 to 1.25$)$ \\
\hline Other antidepressants & 86 & 894 & 1.30 (1.01 to 1.68$)$ & 0.99 (0.76 to 1.29$)$ & 3 & 28 & 1.51 (0.39 to 5.85$)$ & 0.80 (0.16 to 4.06$)$ \\
\hline Co-exposure $\dagger$ & 85 & 522 & 2.55 (1.96 to 3.31 ) & 1.53 (1.15 to 2.04$)$ & 1 & 29 & - & - \\
\hline \multicolumn{9}{|l|}{ Specific SSRIs: } \\
\hline Paroxetine & 289 & 4209 & 1 & 1 & 8 & 135 & 1 & 1 \\
\hline Citalopram & 128 & 1915 & 1.03 (0.83 to 1.29$)$ & 1.01 (0.80 to 1.26$)$ & 2 & 5 & - & - \\
\hline Fluoxetine & 304 & 5239 & 0.88 (0.74 to 1.04$)$ & 0.94 (0.79 to 1.11) & 6 & 159 & 0.60 (0.20 to 1.81$)$ & 0.42 (0.13 to 1.39$)$ \\
\hline Fluvoxamine & 42 & 810 & 0.74 (0.52 to 1.03$)$ & 0.73 (0.52 to 1.04) & 0 & 29 & - & - \\
\hline Sertraline & 91 & 1463 & 0.92 (0.72 to 1.17$)$ & 0.86 (0.67 to 1.10$)$ & 1 & 33 & - & - \\
\hline \multicolumn{9}{|c|}{ Specific tricyclic antidepressants: } \\
\hline Dothiepin & 136 & 2334 & 1 & 1 & 7 & 102 & 1 & 1 \\
\hline Amitriptyline & 66 & 926 & 1.21 (0.89 to 1.65$)$ & 1.18 (0.86 to 1.61) & 2 & 31 & - & - \\
\hline Lofepramine & 68 & 1096 & 1.11 (0.82 to 1.50$)$ & 1.08 (0.79 to 1.47$)$ & 4 & 47 & $1.12(0.30$ to 4.20$)$ & 0.94 (0.24 to 3.61$)$ \\
\hline $\begin{array}{l}\text { Other tricylic } \\
\text { antidepressant }\end{array}$ & 49 & 545 & 1.43 (1.01 to 2.02 ) & 1.19 (0.83 to 1.69$)$ & 2 & 21 & - & - \\
\hline
\end{tabular}

${ }^{*}$ Adjusted for severity of depression; time depression was diagnosed in relation to start of therapy; referral to psychiatrist or psychologist before index day; history of self harm; diagnosis of, or treatment for, anxiety or panic disorder; schizophrenia; antipsychotic drugs; drug misuse; and alcohol misuse.

†Any exposure to more than one antidepressant of same class or different classes. 


\begin{tabular}{|c|c|c|c|c|c|c|c|c|}
\hline \multirow[b]{2}{*}{ Exposure } & \multicolumn{4}{|c|}{ Non fatal self harm } & \multicolumn{4}{|c|}{ Completed suicides } \\
\hline & $\begin{array}{c}\text { Cases } \\
(n=1173)\end{array}$ & $\begin{array}{c}\text { Controls }(\mathrm{n}=18 \\
537)\end{array}$ & $\begin{array}{l}\text { Crude odds ratio (95\% } \\
\text { CI) }\end{array}$ & $\begin{array}{l}\text { Adjusted odds ratio* } \\
(95 \% \mathrm{CI})\end{array}$ & $\begin{array}{l}\text { Cases } \\
(\mathrm{n}=29)\end{array}$ & $\begin{array}{l}\text { Controls } \\
(\mathrm{n}=607)\end{array}$ & $\begin{array}{l}\text { Crude odds ratio (95\% } \\
\text { CI) }\end{array}$ & $\begin{array}{l}\text { Adjusted odds ratio* } \\
(95 \% \mathrm{CI})\end{array}$ \\
\hline \multicolumn{9}{|l|}{$\leq 14$ days: } \\
\hline $\begin{array}{l}\text { Tricyclic } \\
\text { antidepressants }\end{array}$ & 118 & 1643 & 1 & 1 & 5 & 48 & 1 & 1 \\
\hline SSRIS & 242 & 4214 & 0.76 (0.60 to 0.97 ) & 0.77 (0.61 to 0.98 ) & 5 & 117 & 0.51 (0.12 to 2.08$)$ & 0.45 (0.10 to 2.06$)$ \\
\hline \multicolumn{9}{|l|}{ 15-30 days: } \\
\hline $\begin{array}{l}\text { Triyclic } \\
\text { antidepressants }\end{array}$ & 67 & 1231 & 1 & 1 & 1 & 36 & - & - \\
\hline SSRIs & 208 & 3482 & 1.10 (0.82 to 1.48$)$ & 1.11 (0.82 to 1.49$)$ & 4 & 69 & - & - \\
\hline \multicolumn{9}{|l|}{ 31-60 days: } \\
\hline $\begin{array}{l}\text { Tricyclic } \\
\text { antidepressants }\end{array}$ & 77 & 1183 & 1 & 1 & 5 & 87 & 1 & 1 \\
\hline SSRIS & 233 & 3395 & 1.10 (0.84 to 1.44$)$ & 1.17 (0.88 to 1.54$)$ & 4 & 144 & 0.49 (0.12 to 1.95$)$ & 0.44 (0.10 to 2.01$)$ \\
\hline \multicolumn{9}{|l|}{$>60$ days: } \\
\hline $\begin{array}{l}\text { Tricyclic } \\
\text { antidepressants }\end{array}$ & 57 & 844 & 1 & 1 & 4 & 30 & 1 & 1 \\
\hline SSRIs & 171 & 2545 & 1.08 (0.79 to 1.49$)$ & 1.08 (0.78 to 1.50$)$ & 4 & 76 & 0.39 (0.08 to 1.86$)$ & 0.33 (0.07 to 1.66$)$ \\
\hline
\end{tabular}

*Participants exposed to more than one antidepressant or prescribed non-SSRI, non-tricyclic antidepressants (see table 4) included in models but, for presentational purposes, data are not given in table.

†Adjusted for severity of depression; time depression was diagnosed in relation to start of therapy; referral to psychiatrist or psychologist before index day; history of self harm; diagnosis of, or treatment for, anxiety or panic disorder; schizophrenia; antipsychotic drugs; drug misuse; and alcohol misuse.

some of those dispensed are not taken. Greater compliance with SSRIs may distort our comparison of their risks compared with those associated with tricyclic antidepressants. Secondly, we have carried out a large number of hypothesis tests so that some associations we have highlighted may be chance findings. Thirdly, we did not deal with the question of whether people treated with SSRIs are at greater risk of self harm than those with equivalent morbidity who do not receive treatment. We have assessed risk only relative to people receiving tricyclic antidepressants.

\section{Representativeness of the study}

As expected in a cohort of incident depression, the suicide rate in our study (62 per 100000 patient years) was higher than in the general population (9 per 100000 people). ${ }^{11}{ }^{18}$ Of note, no suicides occurred among people receiving antidepressants and younger than 19 years. The incidence of non-fatal self harm was seven times higher than that of around 400/100 000 in 1995 reported in Oxford. ${ }^{19}$ The ratio of cases of non-fatal to fatal self harm (approximately 30:1) in our study approximates to the ratio of the estimated number of hospital presenting episodes of self harm $(n=142000)^{19}$ and suicides in the general population of England and Wales $(\mathrm{n}=5000){ }^{20}$

\section{Potential biases}

Our findings for people younger than 19 are consistent with the results from randomised controlled trials, which have shown an increased risk of suicidal behaviour in children and adolescents exposed to SSRIs ${ }^{5}{ }^{6}$ but may have resulted from confounding by indication. For example, personality disorders and adjustment disorders are particularly associated with self harm, and in primary care, such patients may be given a diagnosis of depression and SSRIs may be prescribed preferentially. The adjustment made for previous episodes of self harm may not fully compensate for a bias introduced in this way.

\section{Strengths of the study}

The main strengths of our study are the large sample size, detailed exposure data, and confounder information. The base population used in our study partly overlaps with that used by Jick et al. ${ }^{8}$ However, their study included patients prescribed antidepressants between 1993 to 1999, whereas ours covered 1995 to 2001 and considered only patients with a first prescription of antidepressants in this period. Furthermore, our approach to the ascertainment of cases of non-fatal self harm and suicides yielded almost four times as many cases, giving us considerably more power than previous studies.

We have endeavoured to control as closely as possible for factors that may be associated both with the risk of suicidal behaviour and the choice of antidepressant. This was also the rationale for the restriction of the study cohort to patients with a first recorded episode of depression and for the comparisons

Table 6 Risk of non-fatal self harm in people prescribed SSRIs compared with tricyclic antidepressants in relation to age

\begin{tabular}{|c|c|c|c|c|}
\hline \multirow[b]{2}{*}{ Exposure } & \multicolumn{4}{|c|}{ Non-fatal self harm } \\
\hline & Cases $(n=1344)$ & Controls ( $\mathrm{n}=19$ 953) & Crude odds ratio $(95 \% \mathrm{CI})$ & Adjusted odds ratio* $(95 \% \mathrm{Cl})$ \\
\hline \multicolumn{5}{|l|}{ 10-18 years $\uparrow:$} \\
\hline Any current use of tricyclic antidepressants & 24 & 493 & 1 & 1 \\
\hline Any current use of SSRIs & 168 & 2148 & 1.73 (1.10 to 2.72$)$ & 1.59 (1.01 to 2.50$)$ \\
\hline \multicolumn{5}{|l|}{ 19-30 years: } \\
\hline Any current use of tricyclic antidepressants & 106 & 1687 & 1 & 1 \\
\hline Any current use of SSRIs & 312 & 5013 & $1.00(0.79$ to 1.27$)$ & 1.04 (0.82 to 1.32$)$ \\
\hline \multicolumn{5}{|l|}{$>30$ years: } \\
\hline Any current use of tricyclic antidepressants & 189 & 2721 & 1 & 1 \\
\hline Any current use of SSRIs & 374 & 6475 & 0.83 (0.69 to 1.01$)$ & 0.86 (0.71 to 1.04$)$ \\
\hline
\end{tabular}

Participants exposed to more than one antidepressant or prescribed non-SSRI, non-tricyclic antidepressants (see table 4) were included in models but, for presentational purposes, data are not given in table.

*Adjusted for severity of depression; time depression was diagnosed in relation to start of therapy; referral to psychiatrist or psychologist before index day; history of self harm; diagnosis of, or *Adjusted for severity of depression; time depression was diagnosed in relation to start of therapy; referral to
treatment for, anxiety or panic disorder; schizophrenia; antipsychotic drugs; drug misuse, and alcohol misuse.

fIncludes nine cases of non-fatal self harm and 86 controls exposed to SSRIs, and no cases and 18 controls exposed to tricyclic antidepressants among patients aged 10 to 14 years. 


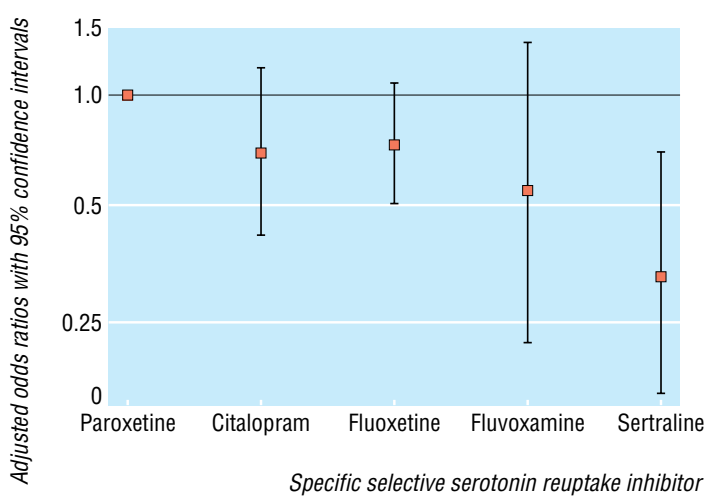

Fig 1 Risk of non-fatal self harm in patients aged 10-18 currently exposed to citalopram, fluoxetine, fluvoxamine, and sertraline compared with paroxetine

within drug classes, thereby minimising confounding by indication operating at a class level.

\section{Conclusion}

As prescribing to adults accounts for over $95 \%$ of antidepressant use in the United Kingdom, our finding that SSRIs and tricyclic antidepressants have a similar risk profile with respect to suicide and non-fatal self harm is reassuring. It is possible, however, that any adverse or protective effects are common to all classes of antidepressants. Further research, based on large randomised trials, should assess the long term and short term risk and benefits of antidepressants and compare these with nonpharmacological therapies for depression in adults.

We thank the ongoing dedicated contribution of clinical and support staff in the general practices, which supply data for the General Practice Research Database, and of the National Vision User Group; E M Bain for help in coding the severity of depression; Klaus Ebmeier for helpful comments on the classification of the antidepressant drug classes; and members of the Medicines and Healthcare products Regulatory Agency Expert Working Group on SSRIs for comments on design, presentation, and methods.

Contributors: All authors contributed to the conception and design or the analysis and interpretation of the data. LW and CM developed the study protocol. DA, DG, JC, SR, SE, and JM contributed to study design and data interpretation. CM and SR were responsible for data extraction and analysis. CM and SR reviewed notes for non-fatal self harm, and CM and DG reviewed notes for potential suicides. DG, LW, and CM wrote the paper with contributions from all authors. The final manuscript was approved by all authors. CM is the guarantor.

Funding: Medicines and Healthcare products Regulatory Agency.

Competing interests: The UK Committee on Safety of Medicines established an expert working group to conduct a review of the safety of SSRIs. No members of the expert working group have financial interests in any of the companies that hold marketing authorisations for SSRIs. The MHRA funded the study and professional staff at the MHRA, including JM and LW, have been acting as secretariat to or observers on the expert working group's review. Neither JM nor LW have any personal financial interests in any drug product. DG, JC, and DA are members of the MHRA's expert working group on the safety of SSRIs, and DA is a member of the Committee on Safety of Medicines. Both act as independent advisers, receiving travel expenses and a small fee for meeting attendance and reading materials in preparation for the meeting. DA has spoken on the methodology of adverse drugs reactions in HIV at a scientific meeting attended by several pharmaceutical companies and sponsored by GlaxoSmithKline (GSK). A honorarium was paid to her department. SE has no personal interests to declare. His department receives funding from many pharmaceutical companies, including GSK, but mainly for methodological research. SE has no direct involvement in any of this. The General Practice Research Database Division receives funding for services, including the conduct of commissioned research, from a wide range of public sector bodies and the pharmaceutical industry. Neither CM nor SR have any competing interests. Ethical approval: General Practice Research Database Scientific and Ethical Advisory Group.

\section{What is already known on this topic}

Selective serotonin reuptake inhibitors (SSRIs) are the most commonly prescribed class of antidepressant.

Evidence from recent clinical trials shows that SSRIs may increase the risk of self harm and suicidal thoughts in children and adolescents

Previous studies of the risk of suicide in adults have been restricted to the four most frequently prescribed antidepressants and have lacked statistical power to identify whether risks differ in children compared to adults

\section{What this study adds}

Risks of self harm and suicide were no different in adults prescribed SSRIs compared with those prescribed tricyclic antidepressants.

Children and adolescents prescribed SSRIs seemed possibly to be at increased risk of self harm compared with those prescribed tricyclic antidepressants

No children taking antidepressants in this study committed suicide

The absence of excess risk of self harm in adult users of SSRIs may be interpreted as reassuring evidence of their safety or that any adverse or protective effects of SSRIs are no different from those seen with other antidepressants.

1 Healy D. Lines of evidence on the risks of suicide with selective serotonin reuptake inhibitors. Psychother Psychosomat 2003;72:71-9.

2 Medawar C, Herxheimer A, Bell A, Jofre S. Paroxetine, Panorama and user reporting of ADRs: Consumer intelligence matters in clinical practice and post-marketing drug surveillance. Int J Risk Saf Med 2002;15:161-9.

3 Medawar C. The antidepressant web. Int J Risk Saf Med 1997;10:75-126.

4 Gunnell D, Ashby D. Antidepressants and suicide: what is the balance of benefit and harm. BMJ 2004;329:34-8.

5 Anonymous. SSRI and venlafaxine use in children. Curr Probl Pharmacovigilance 2003;29:4.

6 Whittington CJ, Kendall T, Fonagy P, Cottrell D, Cotgrove A, Boddington E. Selective serotonin reuptake inhibitors in childhood depression: systematic review of published versus unpublished data. Lancet 2004;363:1341-5.

7 Jick SS, Dean AD, Jick H. Antidepressants and suicide. BMJ 1995;310:215-8.

8 Jick H, Kaye J, Jick SS. Antidepressants and the risk of suicidal behaviors. JAMA 2004;292:338-43.

9 Wood L; Martinez C: The General Practice Research Database: role in pharmacovigilance. Drug Saf 2004, 27:871-81. www.ingentaconnect.com/content/adis/ dsf;jsessionid $=\mathrm{t} 54 \mathrm{q} 6 \mathrm{ekj} 7 \mathrm{~s} 9 \mathrm{~s}$.Victoria (accessed $19 \mathrm{Jan} 2005)$.

10 Breslow N, Dav N. Statistical methods in cancer. Research, volume II: the design and analysis of cohort. studies. Lyons: International Agency for Research on Cancer, World Health Organization: 1987.

11 National Statistics Online. Census 2001. www.statistics.gov.uk/census2001/pop2001/ united_kingdom.asp (accessed 19 Jan 2005).

12 International Conference on Harmonisation of Technical Requirements for Registration of Pharmaceuticals for Human Use. ICH harmonised tripartite guideline. Clinical investigation of medicinal products in the pediatric population. E11. www.ich.org (accessed 28 Jan 2005.

13 Vandenbroucke J. When are observational studies as credible as randomised trials? Lancet 2004;363:1728-31.

14 Buckley NA, McManus PR. Fatal toxicity of serotoninergic and other antidepressant drugs: analysis of United Kingdom mortality data. BMJ 2002;325:1332-3.

15 Zahl D and Hawton K. Repetition of deliberate self-harm and subsequent suicide risk: long term follow-up study of 11583 patients. Br J Psychiatry 2004;185:70-75.

16 Hawton K, Harriss L, Hall S, Simkin S, Bale E, Bond A. Deliberate self-harm in Oxford 1990-2000: a time of change in patient characteristics. Psychol Med 2003;33:987-95.

7 Gunnell D, Frankel S. Prevention of suicide: aspirations and evidence. BMJ 1994;308:1227-33.

18 Brock A, Griffiths C: Trends in suicide by method in England and Wales, 1979 to 2001. Health Stat Q 2003;20:7-17.

19 Hawton K, Fagg J, Simkin S, Bale E, Bond A. Trends in deliberate self-harm in Oxford, 1985-1995. Implications for clinical services and the prevention of suicide. Br J Psychiatry 1997; 171:556-60.

20 National Statistics Online. Trends in suicide by method in England and Wales, 1979 to 2001. www.statistics.gov.uk/downloads/theme_health/HSQ20.pdf (accessed 24 Jan 2005):7-18.

(Accepted 11 January 2005) 
bmj.com 2005;330:389

General Practice Research Database Division, Medicines and Healthcare products Regulatory Agency, London SW8 5NQ

Carlos Martinez epidemiologist

Stephan Rietbrock epidemiologist

Post-Licensing Division, Medicine and Healthcare products Regulatory Agency Lesley Wise epidemiologist

Jane Moseley epidemiologist

Wolfson Institute of Preventive Medicine, Queen Mary, University of London
Deborah Ashby professor of medical statistic.

Department of Psychiatry, University of Edinburgh, Edinburgh

Jonathan Chick consultant psychiatrist

Medical Statistics Unit, London School of Hygiene and Tropical Medicine, London Stephen Evans professor of pharmacoepidemiology

Department of Social Medicine, University of Bristol, Bristol BS8 2PR David Gunnell professor of epidemiology

Correspondence to: C Martinez carlos.martinez@gprd.de 